\title{
Analysis of Integrated Engineering and Social Science Approaches for Projects in Developing Communities
}

\author{
Parry Garff \\ Graduate Student, Sociology Department \\ Brigham Young University \\ Provo, UT 84602 \\ parryfgarff@gmail.com \\ Carol Ward \\ Associate Professor, Sociology Department \\ Brigham Young University \\ Provo, UT 84602 \\ carol_ward@byu.edu
}

\author{
Eric Dahlin \\ Assistant Professor, Sociology Department \\ Brigham Young University \\ Provo, UT 84602 \\ eric.dahlin@byu.edu \\ Randy Lewis \\ Professor, Chemical Engineering Department \\ Brigham young University \\ Provo, UT 84602 \\ randy.lewis@byu.edu
}

\begin{abstract}
Current design methods such as appropriate technology, human-centered design, and participatory design are intended to generate development projects that resonate with users in communities in developing countries. These approaches are extremely useful, but often lack adequate documentation about how to collect data on and incorporate users feedback into the project's design. To address this gap, we introduced social science research methods into a service-learning course for undergraduate engineering students, which culminated in a trip to the communities for whom they were designing, to help students incorporate user feedback into the design of their projects. This paper documents our efforts. One of the main findings from a survey administered to students enrolled in the service-learning course indicate that students exhibited greater awareness of the users' needs, rather than the technical specifications of their projects, after their on-site visit and interviews with users in the community. We conclude by identifying ways students were successful and plans for improving the integration of instruction about social science research methods into the engineering course.
\end{abstract}

Index Terms - Design for Developing Countries, Appropriate Technology, Human-Centered Design, Participatory Design, Social Science Research Methods 


\section{INTRODUCTION}

While there have been many successful development projects, there are still a number of challenges to efforts to ensure that projects will be sustainable and viable. The lessons learned from these challenges demonstrate the critical importance of understanding users' needs and preferences, customs, and technical knowledge in designing projects that are viable and sustainable. ${ }^{\mathrm{i}, \mathrm{ii}, \mathrm{iii}}$ In recent years practitioners and academics have developed approaches to remedy these challenges. Each approach highlights the importance of obtaining user feedback and incorporating the feedback into the design of the project and its implementation. These approaches include human-centered design, appropriate technology, and participatory design. Human-centered design consists of determining and meeting users' needs. Human-centered design helps designers make products that are useful for users in diverse social and cultural contexts. ${ }^{\mathrm{i}, \mathrm{v}}$ Appropriate technology was specifically intended to be used in developing countries and refers to the process of developing environmentally sustainable solutions to problems of poverty that meet the needs of communities while leveraging and developing the skills of users. ${ }^{\mathrm{vi}}$ Appropriate technology depends on collaborative efforts between designer and user to reduce the marginality of groups. ${ }^{\mathrm{xvi}}$ Participatory design goes a step further by providing tools for uniquely partnering with users. In addition to considering user needs and preferences, participatory design underscores the significance of fostering a relationship between the designer and user, where the user participates in the design and co-invention of a customized product. ${ }^{\text {vii,viii }}$

While our view is that current approaches advocated by the development community focus on soliciting and incorporating the expertise of end-users in the design process ${ }^{\mathrm{v}, \mathrm{vi}, \mathrm{xx}}$, these approaches can be strengthened by providing more detailed guidance about how to bridge the gap between designer and user before, during, and after the design process. Existing approaches available to designers for co-creating sustainable solutions with users and maintaining the designer-user relationship are valuable but the methods remain relatively unsystematic and undocumented. Importantly, evaluation research methods in the social sciences and engineering design approaches for developing countries have developed in parallel to become more participatory or user-focused. In general, the integration of engineering approaches to design with social science research-based methods offers an approach that is both systematic and supportive of user-focused design. We believe this integration would benefit from the use of the Social Impact Assessment framework, ${ }^{\text {ix }}$ which emphasizes obtaining critical data about the users and their community context in order to assess the effectiveness of solutions developed. Data collection techniques may include the use of secondary data, ethnographic methods such as interviews and observations as well as survey methods, all of which work together to provide designers with the tools to obtain contextual information and input/feedback from users to inform solutions that are more likely to be successful.

To provide more detailed guidance about how to bridge the gap between designer and user before, during, and after the design process, we describe how we combined engineering and social science research methods in a two-semester university course taught to engineering and technology undergraduate students. The course provides students with opportunities to design and implement humanitarian-based engineering projects for communities in Peru. In addition to technical considerations, students are given instruction about how to identify the needs of community members, communicate with community members, and solicit and incorporate feedback on the design and usefulness of the project. We assess student success by soliciting and incorporating feedback from users and reporting the results of survey data that describes whether 
students engaged users in the design process. We also provide accounts of ethnographic observations of student projects including a washing machine, oven, and reed cutter. We conclude by discussing ways we plan to improve the class in the future.

\section{DESIGN FOR DEVELOPING COUNTRIES}

Design approaches that have been used in developing countries and involve users in the design process include human-centered design, also known as user-centered design; ${ }^{\mathrm{X}}$ appropriate technology; ${ }^{\mathrm{vi}}$ and participatory design. ${ }^{\mathrm{xi}}$ Human-centered design considers information from and about the user as paramount, thus helping to ensure user interests are not marginalized. ${ }^{\text {xii,xiii }}$ Through an iterative process the designer attempts to overcome initial impressions about user needs or wants to discover the product design and features that are most critical. In this process users may or may not be participants in the design process, but users are expected to exert some influence on the process. ${ }^{\text {ix }}$

The appropriate technology framework assumes that collaborative efforts and technology can reduce the marginality of groups. The appropriate technology approach is intended to overcome the limitations of traditional design approaches that are independent of end user input, and do not give enough attention to solutions that consider the needs of marginalized groups. ${ }^{\text {vi }}$ In addition to developing technology with local partners, the broad principles of appropriate technology include keeping product costs to a minimum; awareness of how users feel they will be perceived for using the product; including marginalized groups in the design process; and ensuring the sustainability of the product by making it maintainable, repairable, and reproducible by the community. ${ }^{\text {xiv, xv, vi }}$ Evidence suggests these efforts have been successful to some degree. ${ }^{\text {xvi }}$

Participatory design moves beyond human-centered design and appropriate technology by actively seeking to include the user as a part of the design team. ${ }^{\text {xvii }}$ Participatory design provides designers with ideas about ways to interact with users and seeks to ensure users are not marginalized but that they have a significant voice in the design process. ${ }^{\text {xiii, }}$,iii To overcome communication barriers between the designers and users, for instance, proposals may be in the form of drawings, mock ups, or prototypes. ${ }^{\text {xix }}$ Thus, the user feedback can be provided without needing to learn or talk in more technical terms. ${ }^{\text {xiii }}$

While each of these perspectives provides broad guidance for designing with communities in developing countries, they do not specify the best methods for helping designers overcome cultural differences between the designer and the user in developing countries. Cultural, language and power differentials inhibit accurate user feedback - a core principle of participatory design - which is troublesome for designers. In particular, principles of humancentered and participatory design focus on design features that are compatible with user preferences and characteristics but these approaches are seldom applied in developing countries. Oyugi, Nocera, Dunckley, and Dray $(2008)^{\mathrm{xx}}$ note the challenges of using participatory design in a developing context, all of which relate to differences between designers and the community. The challenges include cultural and language barriers, incompatibility of design techniques and understanding which methods are culturally appropriate, and the inability to communicate and follow-up with users due to geographic distance.

Human-centered design, participatory design, and the appropriate technology approaches often lack sufficient documentation about the appropriate social science research methods needed to generate user feedback and incorporate the feedback into the project design. Appropriate technology suggests designers consider how members in a community will be 
viewed by others in their community for using new technology, ${ }^{\text {xii }}$ but accomplishing this is left up to the designer. Human-centered design comes closest to delivering on the promise of providing a framework for project management in a developing country, yet documentation and evaluation of successful methods is minimal. Human-centered design and participatory design often draw from social science research methods such as interviewing or observing users ${ }^{\text {xii }}$ but projects that have applied these methods in developing countries generally do not provide adequate documentation for employing the appropriate methods and evaluating which ones are most successful.

Using the framework of a university course for which undergraduate engineering students design and implement humanitarian-based projects in Peru, we build on these perspectives by documenting and examining methods that can be used to gather relevant information and feedback from users and involve users in the design process. The course has been in existence since 2007 with projects being implemented in Tonga, Ghana, and Peru. Following project development during the most recent course from September 2012 through May 2013, the students traveled to Peru for two weeks to reconstruct the projects using locally sourced materials and then implement the projects. To apply the principles of human-centered design, appropriate technology and participatory design, students were instructed in class to learn about life in Peruvian communities by reading material and watching videos online, regularly communicating with contacts from the communities, and speaking with other students who had experience living in or working with people in these communities. In addition, students attended a sociology course on research methods where they first received instruction on methods for developing a Community Profile/Needs Assessment. Specific exercises provided them the opportunity to search for information from a variety of secondary sources on relevant economic and cultural and social characteristics and needs of the communities in Peru with whom they would be working. Additional class instruction emphasized participatory research methods and showed students how to use the secondary data they collected as they created interview guides for conducting interviews and engaging in on-going communication with community members in Peru about the projects they were designing. Finally, students were instructed in how to observe community reactions to their projects and obtain relevant feedback for improving designs when they traveled to Peru to meet with community members and demonstrate their project designs.

\section{METHOD}

To evaluate the extent to which students obtained feedback and involved users in the design process, we used research methods appropriate for assessing both student and user experiences with the design process. These methods included survey and ethnographic techniques, as suggested by the Social Impact Assessment approach, which advocates gathering relevant data from all stakeholders ${ }^{\text {ix }}$. We administered two surveys to students and conducted ethnographic observations of the teams as they designed and implemented the projects. The survey instrument included questions about communication with users in Peru while students were in class; information obtained from other sources such as the Internet, course instructor, teaching assistant, and people who have previously lived in or traveled to the communities in Peru; the most common topics discussed relative to project design; team interactions and conflict; experience with foreign languages and living in other countries, and basic demographic characteristics. 
The survey was administered twice to students: the pre-trip survey was administered at the end of the school year prior to the students' visit to Peru. The pre-trip survey assessed the extent to which students communicated with and discussed certain topics using various forms of communication including the telephone, email, etc. The post-trip survey was administered after their return from Peru and evaluated students' face-to-face communication with users. Fourteen students who were in the class and went to Peru completed the pre-trip survey and twelve of the fourteen students completed the post-trip survey. The majority of the students who went to Peru were juniors and seniors and Caucasian. Nine were male and five were female. Most of the students majored in either mechanical engineering (5) or chemical engineering (7) while two students majored in civil engineering.

We used several questions from the survey to examine the extent to which students discussed user needs and lifestyle and obtained feedback from users in Peru while students were involved in the class (pre-trip survey) and while students were in Peru and able to interact face-to-face with users (post-trip survey). First, we asked how often students gathered information about people who would be using the project. The response categories included key information sources in Peru, the Internet, students who previously took the course and reports written about past class projects, and NGOs operating in Peru. Second, the survey asked how often students gathered information about the product design from each of these sources. Third, the survey asked students to identify and rank the three most discussed topics that they discussed as they worked on the project. Students responded to the question by selecting the top three choices from a range of choices that included the ability of users to build or maintain the project themselves, gender norms of users, physical attributes and abilities required to use project (e.g., height, strength), users' lifestyle or daily activities (e.g., household tasks, childcare, employment, leisure time), project's technical specifications, family practices of users, safety of project for the user, community customs or traditions, benefits of the project for the community, community institutions (i.e., religious, political, educational, economic), and other. The analysis in this paper focuses on a subset of the survey responses.

We also conducted ethnographic observations of the classroom instruction and design activities and the team visits to Peru. Results from the observations supplemented the survey data, and more importantly, allowed us to assess more completely whether the teams were successful at involving users and implementing feedback when designing the projects. The projects, which were implemented in Southern Peru, included a washing machine, oven, and reed cutter. The human powered washing machine was designed to reduce the time and effort required to wash clothes and minimize the likelihood users would get wet when washing clothes, which is a problem in the colder months. The second project was a propane-fueled oven that made it possible for users to cook food in an oven at home. The reed cutter project involved developing a method to reduce the time and effort to harvest reeds used for building islands located on a lake (which takes place four days out of every two weeks). Descriptions of each case study in the next section illustrate changes made to the projects as a result of student interactions with community members. 


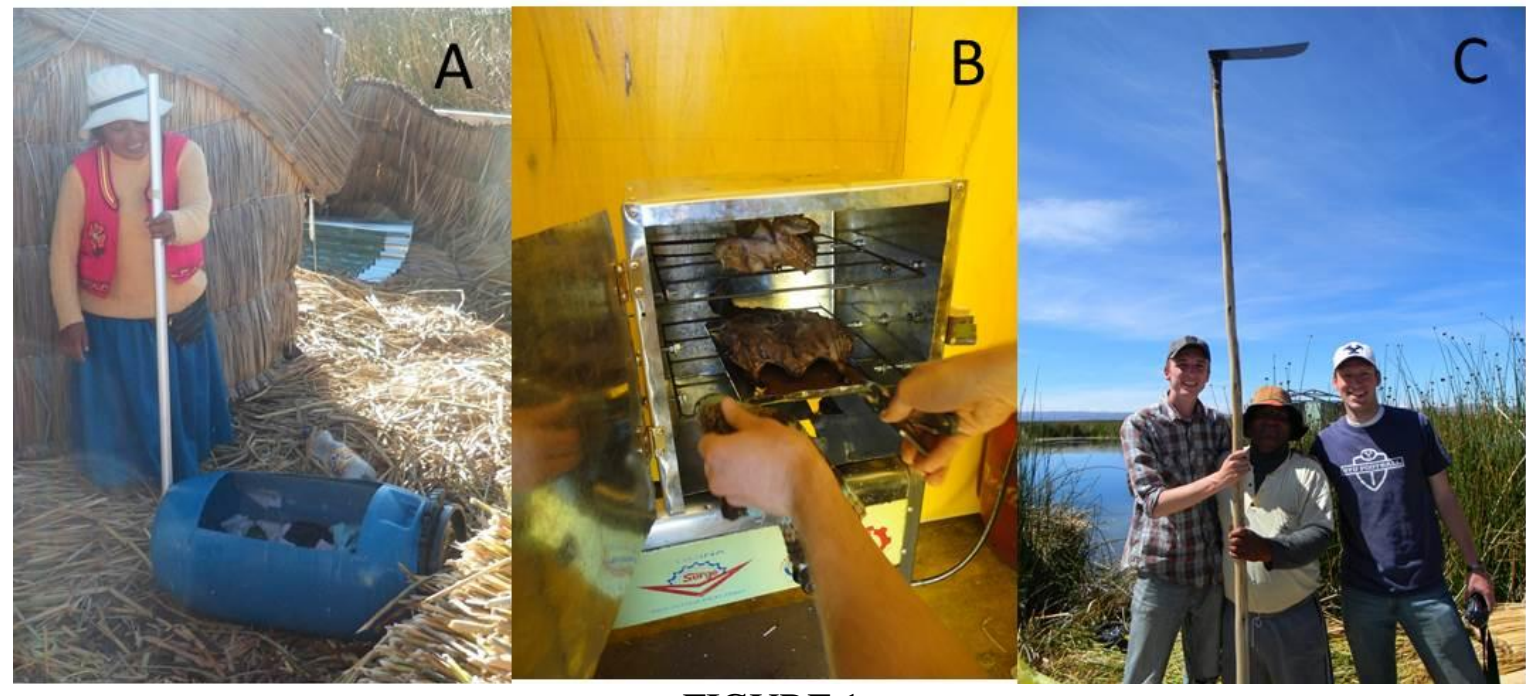

FIGURE 1

STUDENT PROJECTS INCLUDING THE WASHING MACHINE (A), OVEN (B) AND REED CUTTER (C)

\section{RESULTS}

In the pre-trip survey students were asked to identify how often (i.e., never or rarely, once a month, a few times a month or more) they gathered information from various sources about the product design and the people for whom they were designing the projects. The results of these questions are shown in Table I. The various sources that students gathered information from include a phone call and/or email with a member of the community in Peru, reports written about other class projects, the Internet, the course instructor and teaching assistant, other groups in class, NGOs operating in Peru, students who previously took the class, and others who have lived or worked in Peru.

\section{TABLE I}

How OfTEN STUdENTS GATHERED INFORMATION FROM VARIOUS SOURCES ABOUT THE Project Design and People of Peru (Pre-Trip Survey) $(\mathrm{N}=14)$

\begin{tabular}{|l|l|l|l|l|l|l|}
\hline & \multicolumn{2}{|l|}{$\begin{array}{l}\text { How often students gathered } \\
\text { information about the project } \\
\text { design }\end{array}$} & $\begin{array}{l}\text { How often students gathered } \\
\text { information about people } \\
\text { using the project }\end{array}$ \\
\hline & $\begin{array}{l}\text { Never } \\
\text { or rarely }\end{array}$ & $\begin{array}{l}\text { Once a } \\
\text { Month }\end{array}$ & $\begin{array}{l}\text { A few } \\
\text { times a } \\
\text { month or } \\
\text { more }\end{array}$ & $\begin{array}{l}\text { Never } \\
\text { or rarely }\end{array}$ & $\begin{array}{l}\text { Once a } \\
\text { Month }\end{array}$ & $\begin{array}{l}\text { A few } \\
\text { times a } \\
\text { month or } \\
\text { more }\end{array}$ \\
\hline Phone call with contact in Peru & $21 \%$ & $64 \%$ & $14 \%$ & $21 \%$ & $71 \%$ & $7 \%$ \\
\hline Email from contact in Peru & $29 \%$ & $57 \%$ & $14 \%$ & $36 \%$ & $43 \%$ & $21 \%$ \\
\hline Reports written about other class projects & $79 \%$ & $14 \%$ & $7 \%$ & $71 \%$ & $29 \%$ & $0 \%$ \\
\hline Internet & $7 \%$ & $36 \%$ & $57 \%$ & $29 \%$ & $36 \%$ & $36 \%$ \\
\hline Class instructor & $0 \%$ & $7 \%$ & $93 \%$ & $7 \%$ & $7 \%$ & $86 \%$ \\
\hline Class teaching assistant & $0 \%$ & $7 \%$ & $93 \%$ & $0 \%$ & $21 \%$ & $79 \%$ \\
\hline Other groups in class & $29 \%$ & $64 \%$ & $7 \%$ & $43 \%$ & $50 \%$ & $14 \%$ \\
\hline NGOs operating in Peru & $93 \%$ & $7 \%$ & $0 \%$ & $79 \%$ & $21 \%$ & $0 \%$ \\
\hline Students who previously took the class & $50 \%$ & $36 \%$ & $14 \%$ & $36 \%$ & $43 \%$ & $21 \%$ \\
\hline Others who lived or worked in Peru & $93 \%$ & $7 \%$ & $0 \%$ & $71 \%$ & $29 \%$ & $0 \%$ \\
\hline
\end{tabular}


Table I indicates that students used relatively similar resources to gather information about either the people or the project design. The most frequently used source of information about the people and project design included the class instructor and teaching assistant with whom students consulted at least several times per month. Of course, this can be explained by physical proximity and ease of access. The next most common source of information included contacts with people in Peru. However, it should be noted that this occurred typically on a monthly basis. The biggest difference between gathering information about the people and projects was that the Internet was used less for finding information about the people than for finding information about the project design. This may have been due to multiple factors including their crossdiscipline training and paucity of information about the community online. Resources which were easier for students to access were more likely to be the instructor or teaching assistant, the Internet, and phone or email contact compared to information gathered from NGOs, students who took the class previously, or people who had lived in Peru. Interestingly, previous class reports and talking to previous students were not major sources for finding information about either the project or the people in Peru. This would be somewhat understandable if the projects were vastly different from previous years. However, these two sources have a wealth of information related to past projects, the culture of the users, and implementation that could be beneficial for students irrespective of the project. In addition, although more than $65 \%$ of the students at the university have lived abroad for more than a year, students in the class significantly underutilize this resource.

In the pre-trip survey students were also asked to identify the topics discussed most often in their group when working on their project design (Table II). For the most discussed topic, eight out of fourteen students (57\%) identified the project's technical specifications. Two students (14\%) identified the ability of users to maintain project themselves, and three students (21\%) also identified users' lifestyle or daily activities as the most discussed topic. There was greater variation in the second and third most discussed topics. The most commonly selected responses for the second most discussed include benefits for the community ( 3 students, $21 \%$ ) and physical attributes of users (3 students, 21\%). The ability of users to build or maintain the project themselves (3 students, 21\%) and the safety of the user (3 students, 21\%) are the most common responses for the third most discussed topics. The results show students place greater emphasis on the technical aspects of design (e.g., project technical specifications) than on community or social aspects (e.g., users' lifestyle or daily activities). However, community and social aspects were considered by some of the students. There was greater variability of the second and third most discussed topics. 
TABLE II

The Three Most Discussed Topics As Students Worked on Their Project (PRE-TRIP SURVEY) $(\mathrm{N}=14)$

\begin{tabular}{|l|c|c|c|}
\hline & $\begin{array}{c}\text { Most } \\
\text { Discussed }\end{array}$ & $\begin{array}{c}2^{\mathrm{ND}} \text { Most } \\
\text { Discussed }\end{array}$ & $\begin{array}{c}3^{\text {rd }} \text { Most } \\
\text { Discussed }\end{array}$ \\
\hline $\begin{array}{l}\text { Ability for users to build or maintain the project } \\
\text { themselves }\end{array}$ & $14 \%$ & $14 \%$ & $21 \%$ \\
\hline Physical attributes and abilities required to use project & $0 \%$ & $21 \%$ & $14 \%$ \\
\hline Gender norms of users & $0 \%$ & $0 \%$ & $0 \%$ \\
\hline Users' lifestyle or daily activities & $21 \%$ & $7 \%$ & $7 \%$ \\
\hline Family practices of users & $0 \%$ & $7 \%$ & $7 \%$ \\
\hline Projects technical specifications & $57 \%$ & $14 \%$ & $0 \%$ \\
\hline Project safety for the user & $0 \%$ & $7 \%$ & $21 \%$ \\
\hline Benefits of the project for the community & $0 \%$ & $21 \%$ & $14 \%$ \\
\hline Community customs or traditions & $0 \%$ & $0 \%$ & $7 \%$ \\
\hline Community institutions & $0 \%$ & $0 \%$ & $0 \%$ \\
\hline Other & $7 \%$ & $0 \%$ & $0 \%$ \\
\hline Question Unanswered & $0 \%$ & $7 \%$ & $7 \%$ \\
\hline
\end{tabular}

In the post-trip survey there was more variation in the distribution of responses for the most discussed topic. As shown in Table III, only 33\% the students (4 students) responded that the project technical specifications were the most discussed topic. Other students indicated useroriented topics: 17\% (2 students) each selected physical attributes, the users' lifestyle or daily activities, and abilities required to use the project and benefits for the community. The second most discussed topic was the ability for users to maintain the project themselves (33\%) and two students each selected the project's technical specifications, the physical attributes of users and the benefits for the community. The third most discussed topic was the safety of the user (33\%) and two students each selected the projects technical specifications and the ability for users to maintain the project themselves.

TABLE III

The Three Most Discussed Topics As Students Worked on the Project (POST-TRIP SURVEY) $(\mathrm{N}=12)$

\begin{tabular}{|l|c|c|c|}
\hline & $\begin{array}{c}\text { Most } \\
\text { Discussed }\end{array}$ & $\begin{array}{c}\text { 2nd Most } \\
\text { Discussed }\end{array}$ & $\begin{array}{c}\text { 3rd Most } \\
\text { Discussed }\end{array}$ \\
\hline $\begin{array}{l}\text { Ability for users to build or maintain the project } \\
\text { themselves }\end{array}$ & $17 \%$ & $33 \%$ & $17 \%$ \\
\hline Physical attributes and abilities required to use project & $17 \%$ & $17 \%$ & $0 \%$ \\
\hline Gender norms of users & $0 \%$ & $0 \%$ & $0 \%$ \\
\hline Users lifestyle or daily activities & $17 \%$ & $8 \%$ & $8 \%$ \\
\hline Family practices of users & $0 \%$ & $0 \%$ & $8 \%$ \\
\hline Projects technical specifications & $33 \%$ & $17 \%$ & $17 \%$ \\
\hline Project safety for the user & $0 \%$ & $8 \%$ & $33 \%$ \\
\hline Benefits of the project for the community & $17 \%$ & $17 \%$ & $8 \%$ \\
\hline Community customs or traditions & $0 \%$ & $0 \%$ & $8 \%$ \\
\hline Community institutions & $0 \%$ & $0 \%$ & $0 \%$ \\
\hline Other & $0 \%$ & $0 \%$ & $0 \%$ \\
\hline Question Unanswered & $0 \%$ & $0 \%$ & $0 \%$ \\
\hline
\end{tabular}


There were a few notable shifts in the student's responses from the pre-trip survey to the post-trip survey. In the post-trip survey only four students $(33 \%)$ chose the projects' technical specifications as the most discussed item compared to eight students (57\%) in the pre survey. While no student chose benefits to the community as the most discussed topic in the pre-trip survey, two students chose it in the post-trip survey (17\%). As students interacted with the users there was a shift toward the community and away from technical specifications as the top priority of project design. Furthermore, sustainability became a greater priority for the students. In the post-trip survey four out of twelve students chose the ability of the users to maintain the project themselves as the second most discussed item compared to two out of fourteen in the pre survey (from $14 \%$ to $33 \%$ ). There was a shift towards prioritizing the attributes and abilities required to use the project among the most discussed topics. Overall, by working in Peru, the students' priorities shifted from the technical specifications of the projects and towards sustainability, usability, and community benefits. The variability in responses for the post-trip survey compared to the pre-trip survey can likely be attributed to the experience of being on-site and developing a better understanding of both the social and technical conditions that affect the project's success. However, it is unclear if providing students the tools for a greater focus on the social context (vs. technical context) during project development would result in more appropriately aligning the students' priorities toward the community prior to the trip to Peru.

We also report the findings from three case studies of the project designs that illustrate the extent to which students were successful. During the preparation for their trip, the students worked with limited feedback and interaction with the users who were in Peru, typically on a monthly basis. Students were unable to analyze current market offerings or find a substantial amount of documentation on the people or region. They worked to overcome this through various sources of information like phone calls and e-mails with local contacts in Peru prior to visiting the field site. Two students in class spoke fluent Spanish and established good relationships with their Peruvian contacts. The Peruvian contacts were established through many interactions during previous visits to Peru. Students also sent e-mails and pictures to get feedback and maintain a connection to the community before arriving in Peru. The users were only able to get access to phones and email when they visited a nearby city.

Because feedback received through interaction with the contacts prior to the trip was limited, the design process required students to make some assumptions before traveling to Peru. However, assumptions are a part of real world problem solving and allowed students to propose a tentative final solution which would not otherwise be possible. ${ }^{\text {xxi,xxii }}$ Visiting Peru allowed each team to identify and correct several assumptions they had made and make several design changes to their project. The following examples of projects that include a washing machine, oven, and reed cutter illustrate how interactions with community members permitted students to correct their assumptions and incorporate user feedback into the project's design.

The team that designed the washing machine corrected assumptions during their on-site visit that they had made while designing remotely. One of these assumptions related to the project's costs. Keeping costs low was often discussed during the design process, but the team was uncertain about the absolute minimum cost requirements. The team aimed to reduce the cost by removing the door from their original design. However, community members preferred a more expensive machine with a door to keep water from spilling onto the reeds on which the island is built (water dries out the reeds and causes them to wear out faster). Feedback on the washing machine prompted team members to add a door to the washing machine to keep the water from 
escaping and getting the island wet. To keep the island dry, the team added a drain and hose attachment that allowed water to be drained from the washing machine into the lake. Also, to illustrate the participatory design process involved, during construction of the washing machine, a user showed the team how to install the drain without the need of an additional tool (a hammer).

The oven team was able to adjust their assumptions about the size of propane stoves that are typically used in Peru, the desired features for the oven, and the users' cooking skills. First, the design team assumed that the existing propane stoves on which the ovens rested were the same size in Peru as in the United States, but they were smaller in Peru. When the team discovered the ovens they had designed did not fit properly onto the stoves, a bracket was added to stabilize the ovens. Second, the desired features for the oven were different than the team assumed. Based on communication with the women in Peru, the team assumed the highest priority for the oven was its baking capability and designed the racks in the oven to be evenly spaced. The team assumed users would not want an oven rack directly over the burner. However, the men in the community typically treated the oven like a grill and wanted the lowest rack to be closer to the burner. When members of the team observed the men using the oven like a grill, they feared the men would not know when the food was fully cooked, but the men discerned whether the meat was done by watching the color of the meat. After receiving feedback about the oven, the design team changed the design to allow oven racks to meet the need of cooking desired by both men and women. The original design for supporting the rack supports was also too time consuming to modify, so the attachment of the racks was modified to make it easier for users to adjust.

The team responsible for designing the reed cutter assumed a preferred feature would be a replaceable blade, as opposed to the current design with a permanent blade. This assumption was based on communication throughout the year. Interestingly, upon arrival in Peru, the team discovered that users preferred a non-replaceable blade that is secure and set at an angle based on each user's preference. Therefore, a new design was created that included a blade welded onto the end of a reed cutting pole. This was more secure than securing the blade with a wire, which is the design of the cutter the users had previously used that resulted in many lost blades.

There were several positive outcomes from the student's travelling to Peru. As a result of being in Peru the students were able to make important changes to their designs on-site in response to user feedback. Also, during their trip students were able to experience a new culture in meaningful ways. Furthermore, as the results in this section indicate, after students experienced working with local community members in Peru there was a shift in the focus of the students away from technical specifications and towards social context of the community.

\section{DISCUSSION}

Failed development projects are often characterized as underestimating the importance of user experience and preferences for the eventual success of a project; yet, mistakes can be avoided and misunderstandings can be addressed by involving users in the design process. Current views stress getting to know community members, promoting designs based on user needs and preferences, and suggest user participation in the design process. While current perspectives-human-centered design, participatory design, and appropriate technologyprovide valuable insights about user-centered design for developing countries, these perspectives seldom document which methods are most effective. 
To fill this gap we have sought to document our experience integrating engineering and social science, and sought to avoid marginalizing the user and increase user participation and feedback by integrating engineering techniques with social science research methods. We have done this in ways that would help to ensure that design projects resonate with users' social lives and local communities. Specifically, through class instruction on using social science research methods, the engineering students in this study learned how to gather relevant information on the users and their context and appropriate solutions that could be sustained within the community. Students utilized social research methods such as interviewing potential users prior to visiting Peru. Most students reported emailing or speaking on the phone with a contact in Peru once a month. Students also sought information from the course instructor and teaching assistant, both of whom had designed projects for users in Peru, about product design and the people who would be using the project. There are also tremendous benefits to visiting the local community in which designers are working. Table III indicates the value of visiting Peru for students. After visiting Peru, many of the students reported that the topics discussed most often shifted from technical specifications to user and community characteristics.

Being aware of the social context and various social and technological constraints prior to their visit helped students improvise design features when they arrived in Peru. For example, one group that designed a stove discovered that they needed to cook food more quickly. Students were able to modify the stove accordingly because they had tried multiple methods in the classroom and already knew an alternative, viable method of construction. They knew the constraints of this alternate method and that it would work while still maintaining other project constraints such as safety and affordability. While the challenges of designing remotely from the user were not inconsequential, feedback from community members and the course instructor and teaching assistant provided valuable information for prototyping projects prior to students' onsite visit.

Spanish speaking students also fostered and maintained close contact throughout the eight month design process prior to the visit to Peru. Establishing these relationships with the community helped students gather more and better feedback when they arrived at the field site. Because of already established relationships with community members prior to visiting Peru, local contacts became advocates for the students when they arrived and they organized a presentation to be given by the students to community members as well as encouraging community members to provide input and help co-construct projects with the students. These relationships generated trust between students and users that helped community members feel more comfortable providing valuable feedback. In sum, by learning social science research methods, the engineering students were able to understand how technical features resonated with the experience of users within the community and then adapt their projects accordingly. Nevertheless, it remains unclear to what extent misunderstanding can be avoided and user preferences effectively incorporated into the design process while the designers and community members begin their collaboration across such great geographical distance.

Findings from this study suggest several improvements that can be implemented prior to the trip that may help to bridge the distance. First, the results reported in Table I indicate that students were most likely to obtain information from the course instructor and teaching assistant. These are especially appropriate sources of information regarding the technical aspects of the product design. However, students should be contacting users much more often than once a month. This may reduce the amount of adaptation required once students arrive in the country. Individuals and NGOs who live and work in Peru are the most appropriate sources of 
information regarding the people and place. Gathering more information from these sources will create more opportunities for students to learn from those who are familiar with the communities and can assist students in obtaining information and establishing contacts needed for collaborating on project designs. Establishing closer contacts with NGOs will also create a more permanent presence in Peru for the future. In the future, students in the class will be required to gather information about the people of Peru from those who have lived or worked there and have personal experience with life in the community more often. Similarly, students will be required to read reports written by students who have previously taken the course and traveled to Peru. Each year students are required to write reports summarizing their experience. Results from our survey demonstrate that $71 \%$ of students gathering information about the people and $78 \%$ of students gathering information about the product design never or rarely (less than once a month) reviewed these documents.

Second, instructional improvements will include a greater emphasis on social science research methods including more instruction during the beginning of the project development. Students will be given additional training regarding Social Impact Assessment, which will provide students with better understanding of how their designs relate to the social, economic and cultural dimensions of life in the Peruvian communities. By focusing more on Social Impact Assessment students will better understand the potential benefits of the projects for the community as well as cultural and social constraints that need to be considered. Our student survey data showed that during the trip to Peru there was a small shift toward increasing the priority of the discussion of this topic. We hope that a greater emphasis on information about the community during class instruction can help to make this topic a greater priority before students make the trip to Peru.

Lastly, recent work on temporary organizational forms ${ }^{x x i i i}$ are particularly relevant and provide an analogue to NGOs and development practitioners who maintain a temporary presence in a community while attempting to improve living conditions. The temporary nature of some development projects suffer from a lack of knowledge about unobservable customs, traditions, and practices that may impede the project's success. In addition to suffering from a lack of knowledge about a community, having a temporary presence in a community leads developers to be viewed as outsiders. Similarly, temporary organizational forms within communities face challenges to reputation and legitimacy. ${ }^{\text {xiv }}$ If practitioners want to succeed, it is important for them to consider ways to establish legitimacy, and also more generally how innovations diffuse. Consequently, we plan to have students live in the communities with which they are working for a more extended period of time through already existing on-campus internships and study abroad programs. Social science undergraduate and graduate students and interns will accompany engineering students in the future. Establishing a more permanent presence will enhance communication and trust between students and community members, provide opportunities for students to understand better community needs and preferences, and allow students to obtain more detailed feedback and evaluate project implementation.

Other plans include surveys of community members to explore their experience with the projects and the effects of improvements made on the projects. Analysis of the survey data will provide insights into the appropriate methods for obtaining user feedback and participating with users in the design process, which is especially important to assist designers in overcoming cultural, language, and power differences. Data collected through surveys and the other methods will contribute further to filling the gap in documentation of effective methods for successfully integrating social and technical contexts in community work. 


\section{CONClusions}

History is replete with accounts of superior innovations that failed to reach a wide audience because success is not based solely on scientific or technical merit, but also on resonating with the end-users' needs and preferences. Accordingly, as engineers and social scientists integrate their efforts to create technically sound and socially viable projects, current design methods for projects in developing countries will be improved. Current design frameworks like humancentered design, participatory design, and appropriate technology provide valuable guidance for how to design projects that are valuable and useful for users in developing countries, but these approaches will be more successful as they improve their efforts to document and evaluate their methods for obtaining user feedback and involving users in the design process.

This paper reports our attempt to combine engineering and social science methods for design in developing countries. We built on the principles espoused by advocates of human-centered design, participatory design, and appropriate technology as we documented and evaluated the methods used in a service learning course to help student designers create projects that are useful and valuable for community members in Peru. The results of our study of the students enrolled in the service learning course indicate that students often sought help from the course instructor and teaching assistant regarding the project's design and the people using the project. While these sources of information are useful for project design in particular, community members and others who have lived or worked in Peru remained underutilized as informants about the people who would be using the projects. Findings from our study also indicate that students exhibited more awareness of, and sensitivity towards, users after visiting the community, which is unsurprising. But, this finding illustrates the value of on-site visits for providing additional experience with the people and culture for which projects are being designed. Thus the decrease in physical proximity also decreased the distance in social proximity between the student designer and user, which fostered user and community feedback and projects that adapted to user needs and preferences.

We recognize that integrating social science and engineering methods remains a work in process, but we have offered several suggestions for improvement. In addition to establishing better relationships with NGOs operating in the local community to gather information about the users and their cultural practices as mentioned above, we suggest providing additional training about social science research methods such as Social Impact Assessment that allow designers to document and evaluate their endeavors. This training should be early in the design stage. We also advocate that design from a distance should involve more than monthly interaction with the community as well as better utilization of local resources that include previous reports and individuals familiar with the country and/or community. Finally, we advocate establishing a more permanent presence in the local community, whenever possible, to increase the communication and trust between the designers and users. We expect these enhancements to contribute to further integration of engineering and social science methods into a single framework that will result in more effective design projects and solutions that can have positive impact on individuals and communities. 


\title{
REFERENCES
}

\author{
${ }^{\mathrm{i}}$ Francis Wambua Mulwa, "Participatory Monitoring and Evaluation of Community Projects: Community Based \\ Project Monitoring, Qualitative Impact Assessment, and People-Friendly Evaluation Methods." Paulines \\ Publications Africa (2008). \\ ${ }^{i i}$ Richard Heeks, "Information Systems and Developing Countries: Failure, Success, and Local Improvisations." The \\ Information Society: An International Journal 18 (2002): 101-12. \\ iii Israel Dunmade, "Indicators of Sustainability: Assessing the Suitability of a Foreign Technology for a Developing \\ Economy." Technology in Society 24 (2002): 461-71. \\ ${ }^{\text {iv }}$ Mike Cooley, "Human-centered Design.” In Information Design (Cambridge, MA): MIT Press (2000), 65. \\ v IDEO. "Human Centered Design Toolkit 2nd Edition." (2008) (Retrieved on 24th November 2012), \\ http://www.ideo.com/work/human-centered-design-toolkit/ \\ vi Heather M. Murphy, Edward A. McBean, and Khosrow Farahbakhsh, "Appropriate Technology - a \\ Comprehensive Approach for Water and Sanitation in the Developing World." Technology in Society 31 (2009): \\ $158-67$.
}

vii Douglas Schuler, and Aki Namioka, "Participatory Design: Principles and Practices." (Hillsdale, New Jersey): Lawrence Erlbaum Associates, Inc (1993).

viii Jesper Simonsen, and Toni Robertson, "Routledge Handbook of Participatory Design." (New York, New York): Routledge (2012), Xi-Xii.

ix Rabel Burdge, "A Community Guide to Social Impact Assessment (3rd Ed.)" (Middleton, WI): Social Ecology Press (2004).

x Juhani Livari, and Netta Livari, "Varieties of User-Centredness: An Analysis of Four Systems Development Methods." Information Systems Journal 21 (2011): 125-53.

xi Elizabeth B-N. Sanders, "From User-centered to Participatory Design Approaches." In Design and the Social Sciences: Making Connections (London): Taylor \& Francis. (2002).

xii Donald A. Norman, "Cognitive Engineering." In User Centered System Design: New Perspectives on HumanComputer Interaction (Hillsdale, NJ): Lawrence Erlbaum Associates (1986), 31-61.

xiii Kim Goodwin, "Designing for the Digital Age: How to Create Human-centered Products and Services" (Indianapolis, IN): Wiley Publishing, Inc (2011).

${ }^{x i v}$ Robert C. Wicklein, "Designing for Appropriate Technology in Developing Countries." Technology in Society 20 (1998): 371-75.

${ }^{x v}$ Pradip P. Kalbar, Subhankar Karmakar, and Shyam R Asolekar, "Selection of an Appropriate Wastewater Treatment Technology: A Scenario-Based Multiple-Attribute Decision-Making Approach." Journal of environmental management 113 (2012): 158-69.

${ }^{x v i}$ Morag Bell, and Richard Franceys, "Improving Human Welfare through Appropriate Technology: Government Responsibility, Citizen Duty, or Customer Choice." Social Science and Medicine 40 (1995): 1169-79.

xvii Elizabeth B.-N. Sanders, "From User-centered to Participatory Design Approaches." In Design and the Social Sciences: Making Connections (London): Taylor and Francis (2005) 1-8.

xviii Finn Kensing, and Jeanette Blomberg, "Participatory Design: Issues and Concerns." Computer Supported Cooperative Work 7 (1998): 167-85.

${ }^{x i x}$ Elizabeth B.-N. Sanders, Eva Brandt, and Thomas Binder, "A Framework for Organizing the Tools and Techniques of Participatory Design" Participatory Design Conference (2010): 1-4.

xx Cecilia Oyugi, Jose Abdelnour Nocera, Lynne Dunckley, and Susan Dray, "The Challenges for Participatory Design in the Developing World" Proceedings of the Tenth Anniversary Conference on Participatory Design (2008): 295-96.

xxi Dieter Fensel, and Remco Straatman, "Problem-Solving Methods: Making Assumptions for Efficiency Reasons" In Advances in Knowledge Acquisition (Berlin and Heidelberg), Springer, (1996), 17-32.

xxii David Fortus, "The Importance of Learning to Make Assumptions." Science Education 93 (2008): 86-108.

xxiii René M. Bakker, "Taking Stock of Temporary Organizational Forms: A Systematic Review and Research Agenda." International Journal of Management Reviews 12 (2010): 466-86.

${ }_{\text {xxiv }}$ G. Grabher, "Temporary Architectures of Learning: Knowledge Governance in Project Ecologies. " Organization Studies 25 (2004): 1491-514. 